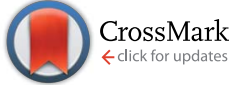

Cite this: RSC Adv., 2016, 6, 104827
Received 6th September 2016 Accepted 24th October 2016

DOI: $10.1039 / c 6 r a 22337 k$

www.rsc.org/advances

\section{Proposition of classification models for the direct evaluation of the quality of cattle and sheep leathers using laser-induced breakdown spectroscopy (LIBS) analysis $\dagger$}

\begin{abstract}
Ariane Maciel Neiva, ${ }^{\text {ab }}$ Manuel Antonio Chagas Jacinto, ${ }^{b}$ Maurício Mello de Alencar, ${ }^{b}$ Sérgio Novita Esteves ${ }^{b}$ and Edenir Rodrigues Pereira-Filho*a

This study proposes classification models for the prediction of the quality parameters of cattle and sheep leathers. In total, 375 leather samples were directly analyzed by laser-induced breakdown spectroscopy (LIBS). Exploratory analysis using principal component analysis (PCA) and classification models employing $K$-nearest neighbor (KNN), soft independent modeling of class analogy (SIMCA), and partial least squares - discriminant analysis (PLS-DA) were the chemometric tools used in the multivariate analysis. The goal was to classify the leather samples according to their quality. The calculated models have satisfactory results with correct prediction percentages ranging from 75.2 (for SIMCA) to 80.5 (for PLS-DA) for the calibration dataset and from 71.6 (for SIMCA) to 80.9 (for KNN) for the validation samples. The proposed method can be used for preliminary leather quality inspection without chemical residues generation.
\end{abstract}

\section{Introduction}

Leather is an important commodity that generates economic gain for several countries. ${ }^{1}$ The conversion of animal skins into leather by tanning processes creates value in these products, which can be used in different segments, for example, leather clothes, bags, shoes, artifacts, furniture and car seats. ${ }^{2}$

In the leather industry, several steps are necessary to convert the raw material into finished leather, such as pre-tanning, tanning, post tanning and finishing operations. ${ }^{3}$ The tanning of most skins is performed with chromium sulfate, but other metal sulfates, and vegetable tannins, can be also used. In these processes, toxic elements that can be incorporated into the leather are added. ${ }^{4}$

The quality evaluation of leathers is fundamental to ensuring their properties. Several physical mechanical tests are performed according to the official methods. ${ }^{5,6}$ However, these tests are laborious, time consuming and destructive; thus, its application is compromised in cases where there is less sample or when the sample cannot be destroyed. ${ }^{7}$ Therefore, alternative methods to these traditional tests are needed. These methods need to present also adequate accuracy and precision and high analytical frequency.
Leather analysis has been performed using inductively coupled plasma optical emission spectrometry (ICP OES), ${ }^{8-10}$ instrumental neutron activation analysis (INAA), ${ }^{11}$ and thermal analysis (TA) techniques. ${ }^{12}$ In addition, direct analysis techniques, such as near-infrared (NIR) spectroscopy, ${ }^{7,13}$ Fourier transform infrared (FTIR) spectroscopy, ${ }^{13}$ and laser-induced breakdown spectroscopy (LIBS), ${ }^{14}$ have been used. However, the use of chemometric tools in leather analysis has still been little explored. An example is the use of NIR to determine the date of production of 130 samples of old leather articles. In this study, the authors employed principal component analysis (PCA) and partial least squares (PLS) for multivariate data evaluation. As a result, it was possible to identify the year of origin of these artifacts. ${ }^{7}$ In a second study ${ }_{13}^{13}$ NIR and FTIR were used to characterize 63 leather samples. The aim of the mentioned study was to identify the finishing treatment (resin, wax, or oil) of the samples using PCA, $K$-nearest neighbor (KNN) and canonical variate analyses (CVA) as the classification techniques. In a third study ${ }^{15} 12$ sheep skin samples were analyzed by NIR spectroscopy (NIRS) from direct determination of the fat in leather, and a Soxhlet was used to obtain reference values. Calibration models employing PLS were prepared using the obtained spectra and the samples were evaluated before and after degreasing.
${ }^{a}$ Grupo de Análise Instrumental Aplicada (GAIA), Departamento de Quimica, Universidade Federal de São Carlos, São Carlos, São Paulo State, 13565-905, Brazil. E-mail: erpf@ufscar.br; Fax: +55 16 3351-8350; Tel: +55 16 3351-8092

${ }^{b}$ Embrapa Pecuária Sudeste, São Carlos, São Paulo State, 13560-970, Brazil $\dagger$ Electronic supplementary information (ESI) available. See DOI: $10.1039 / \mathrm{c} 6 \mathrm{ra} 22337 \mathrm{k}$ 
The emission spectra obtained by LIBS generate large amount of data, and the association with chemometric tools is mandatory in several cases. This combination has been widely used for classification or discrimination of different types of samples, such as toys (PCA, KNN, Soft Independent Modeling of Class Analogy, SIMCA and PLS for discriminant analysis, PLSDA) ${ }^{16}$ soils (SIMCA and linear discriminant analysis, LDA) ${ }^{17}$ pharmaceutical tablets (SIMCA and PCA), ${ }^{18}$ wheat grains (PLSDA) ${ }^{19}$ inks and pigments (PCA, SIMCA and PLS-DA), ${ }^{20}$ biomaterials and chemical warfare simulants (PCA and SIMCA), ${ }^{21}$ plants (PCA and SIMCA), ${ }^{22}$ soils and rocks (SIMCA and PCA), ${ }^{23}$ polymeric fractions of scrap from mobile phones (KNN, SIMCA and PLS-DA), ${ }^{24,25}$ powdered uranium concentrate (PCA and SIMCA). ${ }^{26}$

This study presents a combination of LIBS emission spectra with classification models. Reference values obtained via physical mechanical testing of leather were used to calculate the classification models. These models were established using 3 different chemometric techniques: (1) in the KNN model, the Euclidean distance among samples is used to classify nearest neighbors; ${ }^{27}$ (2) in SIMCA, a PCA is calculated for each class; ${ }^{27}$ and in (3) PLS-DA, the model must define the dependent variables, and a model is calculated using PLS-factors. ${ }^{27,28}$

Thus, the goal of this study is to evaluate the use of LIBS spectra combined with classification models, KNN, SIMCA and PLS-DA as an alternative to physical and mechanical tests for evaluation the quality of leather.

\section{Experimental}

\section{Samples and physical mechanical tests}

In the experiments, 375 leather samples were used with 60 from sheep and 315 from cattle. These samples were tanned with chromium (semi-finished and finished leather) and obtained

Table 1 Descriptions of the leather samples used in this study

\begin{tabular}{|c|c|c|}
\hline Remarks & Sheep leather & Cattle leather \\
\hline $\begin{array}{l}\text { Intended } \\
\text { application }\end{array}$ & Shoes & Shoes and car seats \\
\hline Color & Brown (60 samples) & $\begin{array}{l}\text { Hazel (17), dark hazel (57), } \\
\text { light hazel (112), green (112) } \\
\text { and black (17 samples) }\end{array}$ \\
\hline Manufacture stage & Finished leather & $\begin{array}{l}\text { Semi-finished and } \\
\text { finished leather }\end{array}$ \\
\hline Year of slaughter & 2006 & 2010 and 2011 \\
\hline Genetic groups $^{a}$ & DOR, SIN and SUF & $\begin{array}{l}\text { CANE, CASN, CATA, } \\
\text { HNE, HSN, and HTA }\end{array}$ \\
\hline $\begin{array}{l}\text { Age of the animals } \\
\text { (days) }\end{array}$ & $104-201$ & $342-725$ \\
\hline $\begin{array}{l}\text { Weight of the } \\
\text { animals (kg) }\end{array}$ & $28.7-41.7$ & $292-579$ \\
\hline \multicolumn{3}{|c|}{$\begin{array}{l}{ }^{a} \text { DOR: Dorper; SIN: Santa Inês; SUF: Suffolk; CANE: father Canchin and } \\
\text { mother Nelore; CASN: father Canchin and mother } 1 / 2 \text { Senepol }+1 / \\
\text { 2Nelore; CATA: father Canchin and mother } 1 / 2 \text { Angus }+1 / 2 \text { Nelore; } \\
\text { HNE: father Hereford and mother Nelore; HSN: father Hereford and } \\
\text { mother } 1 / 2 \text { Senepol }+1 / 2 \text { Nelore; HTA: father Hereford and mother } 1 / \\
2 \text { Angus }+1 / 2 \text { Nelore. }\end{array}$} \\
\hline
\end{tabular}

from animals bred at Embrapa Pecuária Sudeste. These animals presented different characteristics, such as genetic group, sex, weight, and age. The experiment was approved by the Animal Research Ethics Committee of Embrapa Pecuária Sudeste (CEUA/CPPSE, Protocol No. 04/2011). This committee follows the law number 11794 (October, 08, 2008) that regulates the incise VII of first paragraph of article 225 from the Brazilian Federal Constitution. This law establishes procedures for experiments with live subjects (http://www.mct.gov.br/ upd_blob/0238/238343.pdf). Other characteristics including the place and year of slaughter were also observed in the data evaluation. A complete description (the intended application purpose, color, process step, etc.) of the analyzed samples can be seen in Table 1.

To perform LIBS analysis, each animal leather sample was cut into a rectangle $(3.00 \mathrm{~cm} \times 4.00 \mathrm{~cm})$ using a hydraulic press (Metalúrgica Aço real, P-23) with cutting knives.

To obtain reference values for the classification models, all samples were submitted to 18 physical and mechanical tests. These tests were divided in two directions: 9 longitudinal (L) and 9 transversal $(\mathrm{T})$. Samples from $\mathrm{L}$ and $\mathrm{T}$ directions were obtained parallel to the cranial-caudal axis of the animal, according to ABNT NBR ISO 2418:2015. ${ }^{6}$ The tests comprise samples intended to be used in car seats or shoes.

After slaughtering, the skins were subjected to the tanning process and tanned with chromium(III) sulfate. After tanning, six leather test specimens of each skin were collected with razors in a hydraulic press with 3 in the $\mathrm{L}$ and 3 in the $\mathrm{T}$ directions (ABNT NBR ISO 2418:2015). ${ }^{6}$ Before performing the tests, the leather test specimens were conditioned for 48 hours at $23 \pm 2{ }^{\circ} \mathrm{C}$ and relative humidity of $50 \pm 5 \%$ (ABNT NBR 10455:2014). ${ }^{29}$ Then, the thicknesses of the leather test specimens were measured (ABNT NBR ISO 2589:2014). ${ }^{30}$ Finally, the physical and mechanical tests were performed using a dynamometer (Maqtest), and four different tests were performed: determination of the tensile strength (ABNT NBR ISO $3376: 2014) ;^{31}$ percentage extension or elongation of leather (ABNT NBR ISO 3376:2014); ${ }^{31}$ determination of tear strength, tongue tear of leather (ABNT NBR ISO 3377-1:2014); ${ }^{32}$ and tear strength of leather, double hole (ABNT NBR ISO 3377-2:2014). ${ }^{33}$ The equipment measures the strength $(\mathrm{N})$ required to break or tear the leather, and using this value and the thickness or area, the resistance is calculated in $\mathrm{N} \mathrm{mm}^{-1}$ or $\mathrm{N} \mathrm{mm}^{-2}$ according to the standards mentioned above. The resistance values were calculated by dividing the strength $(\mathrm{N})$ for tear strength by the thickness $(\mathrm{mm})$ and the tensile strength was calculated by dividing the strength $(\mathrm{N})$ by the area $\left(\mathrm{mm}^{2}\right)$.

\section{LIBS: parameters optimization and analysis}

In this study, a J200 LIBS instrument was used (Applied Spectra, Fremont, CA, USA) with Axiom 2.5 software. This instrument is equipped with a Nd:YAG laser emitting at a fundamental wavelength of $1064 \mathrm{~nm}$ delivering a maximum of $100 \mathrm{~mJ}$ energy in a single laser pulse at a frequency of $10 \mathrm{~Hz}$. A 6-channel CCD spectrometer is used to record the spectral information from 186 to $1042 \mathrm{~nm}$ : channel 1: 186 to $309 \mathrm{~nm}$; channel 2: 309 to 
$460 \mathrm{~nm}$; channel 3: 460 to $588 \mathrm{~nm}$; channel 4: 588 to $692 \mathrm{~nm}$; channel 5: 692 to $884 \mathrm{~nm}$; channel 6: 884 to $1042 \mathrm{~nm}$; spectral resolution $<0.1 \mathrm{~nm}$ from UV to Vis and $<0.12 \mathrm{~nm}$ from Vis to NIR and the spectra are composed of 12288 variables. In the experimental setup, three instrumental parameters can be varied: laser energy from 0 to $100 \mathrm{~mJ}$, delay time from 0 to $2 \mu \mathrm{s}$ and spot size from 50 to $250 \mu \mathrm{m}$. These three parameters were evaluated initially using a full factorial design and later a Doehlert design to establish a commitment condition for all emission lines evaluated. ${ }^{34}$

The full factorial design is used in the first stage of optimization to identify the influence or effect of each variable on the desired response. ${ }^{35}$ After the identification of the most important variables, a refinement of the data can be done by adding more levels of the factorial design, using other planning as the design Doehlert. Using this type of design, the variables can be tested in different levels and the most important one can be studied with more details. ${ }^{35}$

The samples were analyzed directly in the ablation chamber without any preliminary treatment. Before the experiments, a cleaning process using several laser pulses was performed. After that, a total of 100 spectra were collected for each sample in raster mode.

In the beginning, the 3 experimental parameters mentioned before were evaluated at two levels using a full factorial design $\left(2^{3}=8\right.$ experiments): laser energy (50 and 80 $\mathrm{mJ})$, delay time $(0.5$ and $1.0 \mu \mathrm{s})$ and spot size $(50$ and $100 \mu \mathrm{m})$. These analyses were performed on the front and back of 15 previously selected representative samples (sheep and cattle leathers). The evaluated responses were the signal-tobackground ratio (SBR) for the 5 most intense emission lines for $\operatorname{Cr}(283.5,357.8,359.3,425.4$ and $427.4 \mathrm{~nm})$. Seven effects ( 3 main effects, 3 secondary effects and 1 tertiary effect) were calculated for each emission line, and their average was

Table 2 Doehlert design performed for optimization of the laser energy, delay time and spot size conditions and the global desirability calculated for each experiment at $359.0 \mathrm{~nm}$

\begin{tabular}{llll}
$\begin{array}{l}\text { Laser } \\
\text { energy }(\mathrm{mJ})\end{array}$ & $\begin{array}{l}\text { Delay time } \\
(\mu \mathrm{s})\end{array}$ & $\begin{array}{l}\text { Spot size } \\
(\mu \mathrm{m})\end{array}$ & $\begin{array}{l}\text { Global } \\
\text { desirability }\left(D_{\mathrm{g}}\right)\end{array}$ \\
\cline { 1 - 2 }
\end{tabular}

Experiment Coded Real Coded Real Coded Real 359 nm

\begin{tabular}{lcccccrl}
\hline 1 & 0 & 50 & 0 & 1.0 & 0 & 75 & 0.26 \\
2 & 0 & 50 & 0 & 1.0 & 0 & 75 & 0.33 \\
3 & 0 & 50 & 0 & 1.0 & 0 & 75 & 0.17 \\
4 & 1 & 90 & 0 & 1.0 & 0 & 75 & 0.74 \\
5 & 0.5 & 70 & 0.866 & 1.9 & 0 & 75 & 1.00 \\
6 & 0.5 & 70 & 0.289 & 1.3 & 0.817 & 100 & 0.71 \\
7 & -1 & 10 & 0 & 1.0 & 0 & 75 & 0.00 \\
8 & -0.5 & 30 & -0.866 & 0.1 & 0 & 75 & 0.19 \\
9 & -0.5 & 30 & -0.289 & 0.7 & -0.817 & 50 & 0.81 \\
10 & 0.5 & 70 & -0.866 & 0.1 & 0 & 75 & 0.56 \\
11 & 0.5 & 70 & -0.289 & 0.7 & -0.817 & 50 & 0.74 \\
12 & -0.5 & 30 & 0.866 & 1.9 & 0 & 75 & 0.42 \\
13 & 0 & 50 & 0.577 & 1.6 & -0.817 & 50 & 0.77 \\
14 & -0.5 & 30 & 0.289 & 1.3 & 0.817 & 100 & 0.10 \\
15 & 0 & 50 & -0.577 & 0.4 & 0.817 & 100 & 0.33
\end{tabular}

used to rank the influence of the variables in the spectral condition.

After the identification of the order of the most important variables, a Doehlert design was also performed. In this experiment, the variables can be studied at different levels. Table 2 shows the 15 experiments performed for the two samples chosen for optimization, i.e., one cattle leather sample and one sheep leather sample. In this new design, the SBRs and analytical signal intensities were considered for the 5 most intense emission lines for $\mathrm{Cr}$. These data were converted into desirability, and the lower and higher values were coded as 0 and 1 , respectively. The 3 first experiments described in Table 2 represent the central point, and they were performed to calculate the sum of the square of the pure error (SSPE). In these 3 experiments, the variables are coded as 0 , and the laser energy, delay time and spot size are $50 \mathrm{~mJ}, 1.0 \mu \mathrm{s}$ and $75 \mu \mathrm{m}$, respectively. All experiments were performed in aleatory order.

In the optimization, 15 models were calculated ( 5 for cattle, 5 for sheep and 5 for both) using the 5 most intense Cr emission lines. The parameters of the models were evaluated using an ANOVA (analysis of variance) table. Surface plots were obtained for the calculated models allowing identification of the most adequate conditions for all samples simultaneously.

\section{Data analysis and classification models}

The raw data were normalized by the individual area, ${ }^{36}$ averaged over 100 pulses and mean centered. The dataset was organized using Microsoft Excel, and a routine was developed for data normalization using Matlab 2009 (The Math Works, Natick, USA). Aurora software (Applied Spectra) was employed for emission lines identification, and Pirouette 4.5 (Infometrix, Bothell, USA) was used for the data classification models calculation.

The dataset consisted of a matrix with 375 rows $\times 12288$ columns, in which the rows represented the leather samples and the columns represented the emission lines (from 186 to $1042 \mathrm{~nm}$ ). An initial exploratory analysis using PCA was performed to evaluate whether LIBS could differentiate several sample characteristics: colors, type of animal, finished or semifinished leather, among others. Later, three classification models were proposed for predicting the quality of the leathers: KNN, ${ }^{27}$ SIMCA $^{37}$ and PLS-DA. ${ }^{38}$ Classification and validation datasets were separated using the Kennard-Stone algorithm. ${ }^{39}$ The classification set was composed of $80 \%$ of the samples, and the validation set was composed of $20 \%$ (see details in Table S1, in the ESI $\dagger$ ). These classification models combine emission signals that reflect the quality of leather analyzed.

\section{Results and discussion}

\section{Optimization of LIBS experimental conditions}

Initially, three experimental parameters for the LIBS technique were evaluated by full factorial design. Fig. S1 (in the ESI $\dagger$ ) shows a probability plot of the seven effects calculated. Using this plot, the most important effects were ranked: delay 

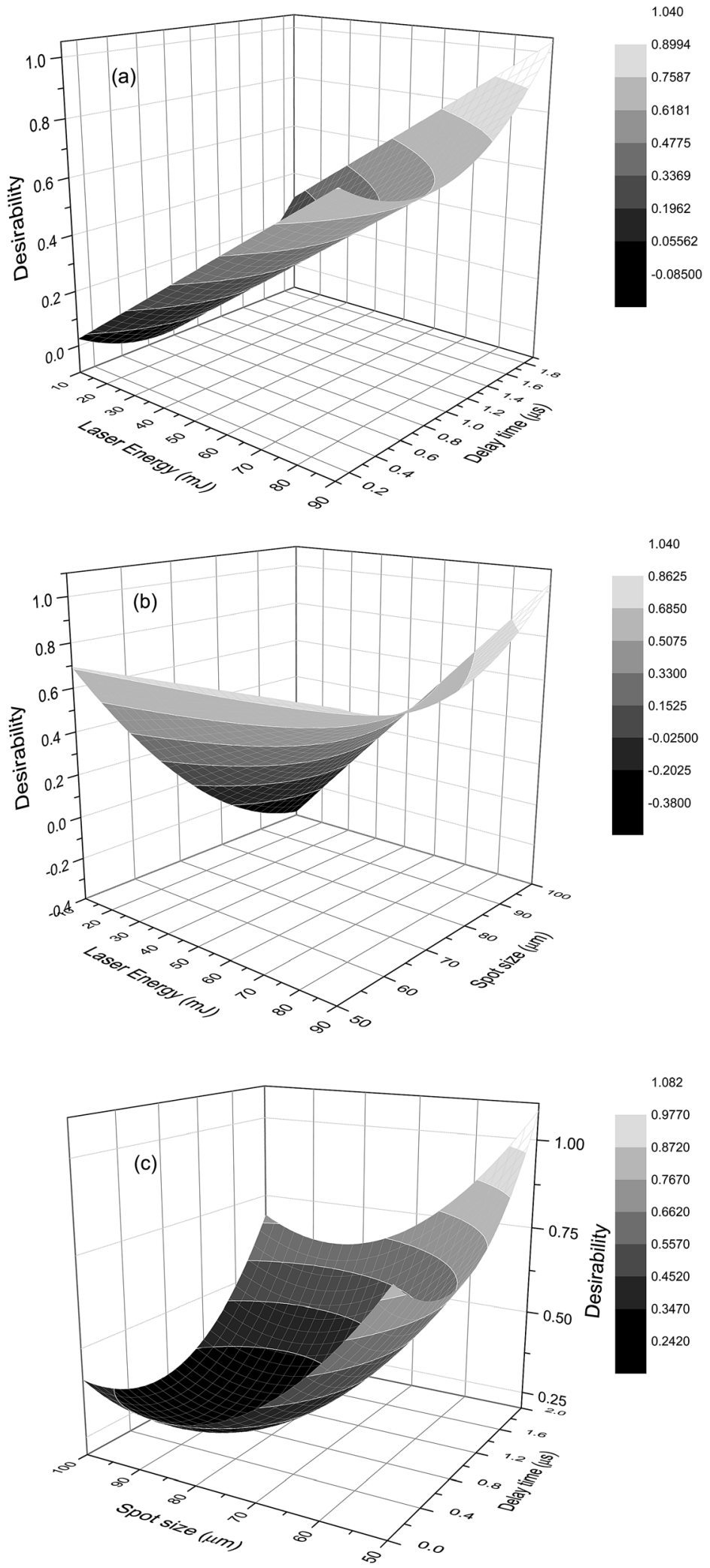

Fig. 1 Surface plots obtained for $D_{\mathrm{g}}$ from responses obtained at $359 \mathrm{~nm}$ : delay time versus laser energy (a), laser energy versus spot size (b) and delay time versus spot size (c).

time (2), laser energy (1), the interactions between laser energy and delay time (12) and the laser energy and spot size (13). High laser energy and low delay time produces positive effects. The spot size (3) did not have a significant influence, but there are interactions between this variable and the others. 
Given these results, a refinement of the data was performed by varying the most important variables with more levels using a Doehlert design (see Table 2). Laser energy was varied across 5 levels $(10,50,65,80$ and $90 \mathrm{~mJ})$, delay time (the most important variable) across $7(0,0.25,0.5,0.75,1.0,1.5$ and $2.0 \mu \mathrm{s})$ and spot size (the least important) across $3(50,75$ and $100 \mu \mathrm{m})$; the monitored responses were converted to desirability. In this case, the lowest and the highest SBR and intensity were converted to 0 and 1 , respectively. In the beginning, calculating a global model was attempted by combining the 5 emission lines monitored in both types of leathers (cattle and sheep), but it was not possible to obtain a valid model. Then, individual models were calculated for each emission line in each type of leather, and only the emission line at 359.0 in cattle leather presented a regression model without a lack of fit.

Table 2 also shows the global desirability $\left(D_{\mathrm{g}}\right)$ calculated at $359.0 \mathrm{~nm}$ for each experiment. The generated model (only the valid coefficients) is represented by eqn (1):

$$
\begin{aligned}
& D_{\mathrm{g}}(359 \mathrm{~nm}, \text { cattle })= \\
& \underset{ \pm 0.11}{0.31}+\underset{ \pm 0.13}{0.37} \mathrm{LE}+\underset{ \pm 0.13}{0.16 \mathrm{DT}}-\underset{ \pm 0.13}{0.24} \mathrm{SS}+\underset{ \pm 0.22}{0.29} \mathrm{DT}^{2} \\
& +\underset{ \pm 0.21}{0.32} \mathrm{SS}^{2}+\underset{ \pm 0.31}{0.41 \mathrm{LE} \times \mathrm{SS}}
\end{aligned}
$$

where LE, DT and SS are the laser energy, delay time and spot size, respectively.

The significance of this model was evaluated using an ANOVA, and the statistical parameters are presented in Table S2 (in the ESI†).

In this model, it is possible to see that there is a strong synergism (this is the highest coefficient in eqn (1)) between the laser energy (LE) and the spot size (SS). The calculated model did not show lack of fit because when the mean of the squares of the lack of fit and the pure error are statistically the same, the calculated $F$ value (2.26) is lower than the tabulated one (19.3) with a 95\% confidence level (see Table S2, in the ESI $\dagger$ ). The correlation coefficient $\left(R^{2}\right)$ was 0.927 .

The surface responses obtained from this model are presented in Fig. 1. The laser energy ( $x$-axis), delay time ( $y$-axis), and $D_{\mathrm{g}}$ (z-axis) are shown in Fig. 1a. The best working conditions are obtained with a laser energy of $90 \mathrm{~mJ}$ and a delay time of $1.9 \mu \mathrm{s}$ (the predicted $D_{\mathrm{g}}$ is approximately 1 ). Fig. $1 \mathrm{~b}$ and c shows the other combinations of the variables (laser energy and spot size and delay time and spot size). Analyzing these figures, it is possible to see that high $D_{\mathrm{g}}$ is observed when the spot size is 100 or $50 \mu \mathrm{m}$.

Thus, a new experiment was performed by keeping the variables already optimized at $90 \mathrm{~mJ}$ and $1.9 \mu$ s and varying only the spot size to 50 or $100 \mu \mathrm{m}$. The spot size of $50 \mu \mathrm{m}$ showed the best desirability results. Thus, to validate the model, the optimized conditions were also tested for the other $4 \mathrm{Cr}$ emission lines in both types of leather. This condition was compared with the most intense signal previously obtained in the Doehlert design before optimization. In all cases, the signal intensity significantly improved after optimization (see Fig. 2).

In addition, after laser pulse and visual inspection none unusual damage was noted in the samples (see Fig. S2 at ESI $\dagger$ ).
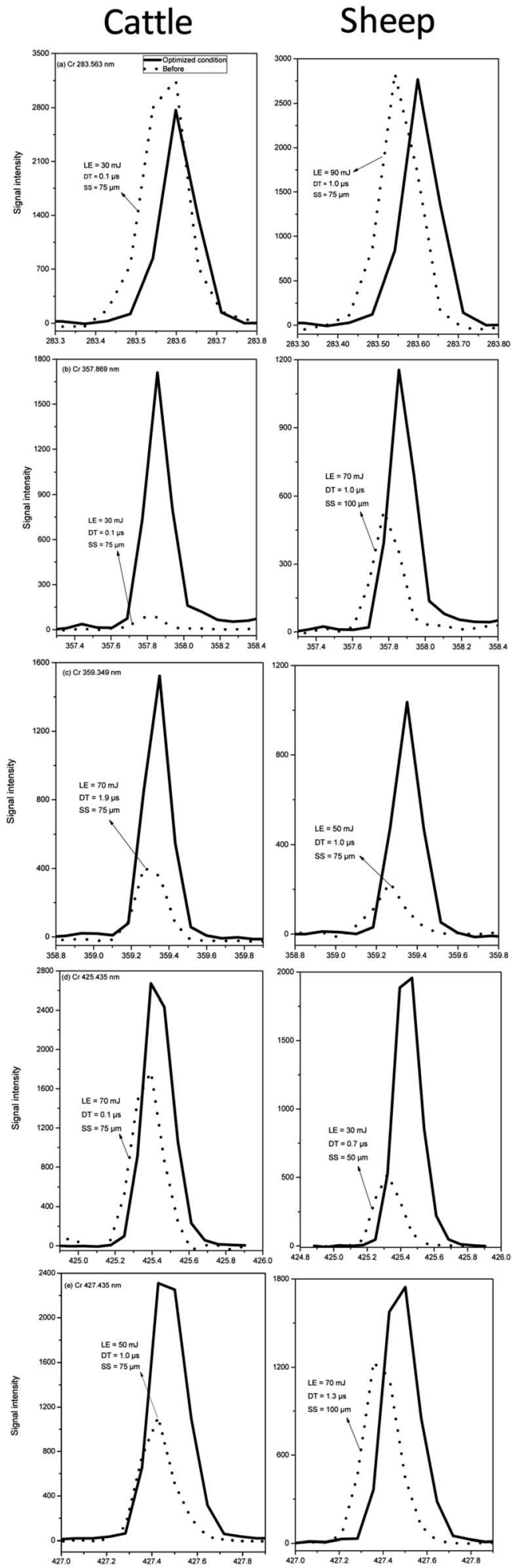

\section{Emission line $(\mathrm{nm})$}

Fig. 2 Emission signals for the 5 most intense $\mathrm{Cr}$ lines for leather samples (cattle and sheep) after and before experiments for LIBS parameter optimization. 


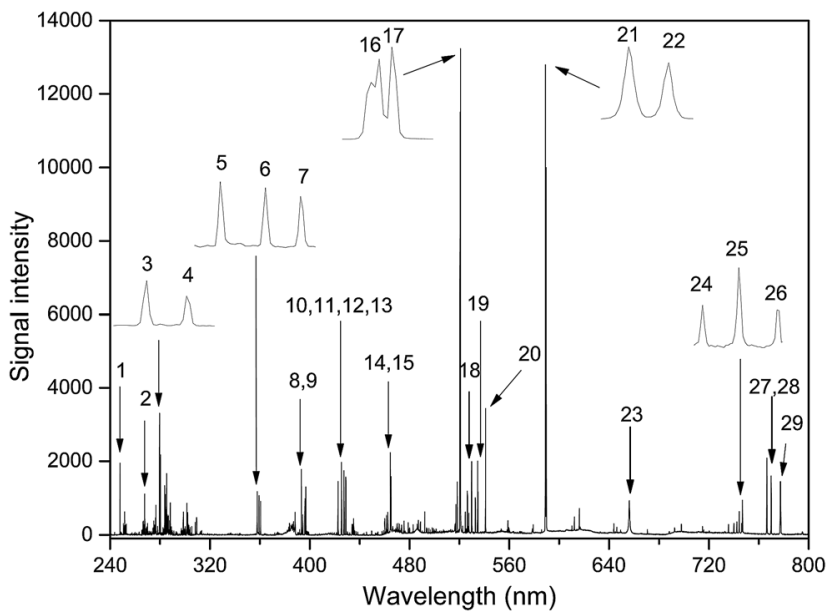

Fig. 3 Typical emission spectra obtained for a leather sample.

It is also important to mention that it is hard to perform a fair comparison among the published paper because different instrumental setups are described. In a paper published in $2011,{ }^{18}$ for example, the energy was $25 \mathrm{~mJ}$, but the laser wavelength was $532 \mathrm{~nm}$. Yet in 2011 Nasr et al. ${ }^{14}$ published a paper dedicated to the analysis of leather and the laser energy and wavelength were $100 \mathrm{~mJ}$ and $1064 \mathrm{~nm}$, respectively. The main advantage of the present study is the fact that now exactly the same experimental conditions can be reproduced worldwide, because a commercial system is used. The calculated irradiance for the operational conditions used was $765 \mathrm{GW} \mathrm{cm}^{-2}$.

\section{Analysis of the leathers}

Fig. 3 presents a general description of a representative LIBS spectra obtained from a leather sample (sheep). This spectrum is an average of 100 spectra. The identified and most intense signals are highlighted and numbered from 1 to 29 , and their corresponding emission lines are listed in Table 3 . The majority of the emission lines identified are from $\mathrm{Cr}$ as expected due to the leather tanning process with chromium(III) sulphate. The most intense emission lines were observed for $\mathrm{Cr}$ and $\mathrm{Na}$ at 520.8 (peak 17) nm and 588.9 (peak 21), respectively. These two chemical species, as well as others found in the leather samples, are from several chemical reagents added in the tanning processes. $^{8-11}$

In order to evaluate the spectrum reproducibility, several calculations using 100 spectra obtained in raster mode (a line) in a sample were performed. After that, signal height for the following emission lines were calculated ( $5 \mathrm{Cr}$ emission lines): 267.7, 357.8, 359.3, 425.4 and $427.4 \mathrm{~nm}$. Then, 10 ratios were evaluated (267/357, 267/359, 357/359, 425/427, 267/425, 267/427, $359 / 425,357 / 427,359 / 427$ and 357/425). Fig. S3 (at ESI†) shows box plot graphics for the 10 calculated ratios. As can observe the values are constant and follow a normal distribution.

\section{Exploratory analysis using PCA}

PCA is a tool that allows to project high dimensional data set in a small number of variables (named principal component, PC), allowing to observe differences and verify relations among variables. ${ }^{27}$ Two new matrices are generated in a PCA, a loading matrix that represents the weight of the original variables and a score matrix with the projections of the samples. ${ }^{28}$

A PCA analysis was calculated using the obtained data matrix (375 samples and 12288 variables) with the normalized and mean-centered dataset. Several categories were analyzed, but differences were only observed when the leather color was considered. The scores and loadings for first three principal components were evaluated, and Fig. 4a presents the scores values plot for PC1 for different samples, with $74 \%$ of the explained variance, while Fig. $4 \mathrm{~b}$ presents the loadings plot for PC1 at different wavelengths. The main distinction of the samples as the color is due to the $\mathrm{C}, \mathrm{Cr}$ and $\mathrm{Na}$ with positive values for PC1 and Ca with negative. The other PCs are presented in the ESI, and Fig. S4 and S6† show scores plots for PC2 and PC3, while Fig. S5 and S7 (all in ESI $\dagger$ ) show their respective loadings, presenting emission lines that can be associated with the pigments used in the samples. ${ }^{24}$

Table 3 Emission lines (I atomic and II ionic) identified in the analyzed leathers

\begin{tabular}{|c|c|c|c|c|c|}
\hline Identification & Elements & Wavelength (nm) & Identification & Elements & Wavelength (nm) \\
\hline 1 & C I & 247.8 & 16 & Cr I & 520.6 \\
\hline 2 & Cr II & 267.7 & 17 & Cr I & 520.8 \\
\hline 4 & $\mathrm{Mg} \mathrm{I}$ & 280.1 & 19 & Cr I & 534.5 \\
\hline 5 & Cr I & 357.8 & 20 & Cr I & 540.9 \\
\hline 6 & Cr I & 359.3 & 21 & $\mathrm{Na} \mathrm{I}$ & 588.9 \\
\hline 9 & Ca II & 396.8 & 24 & $\mathrm{~N} \mathrm{I}$ & 742.3 \\
\hline 10 & $\mathrm{Ca} \mathrm{I}$ & 422.6 & 25 & N I & 744.2 \\
\hline 11 & Cr I & 425.4 & 26 & N I & 746.8 \\
\hline 12 & Cr I & 427.4 & 27 & K I & 766.4 \\
\hline 13 & Cr I & 428.9 & 28 & K I & 769.8 \\
\hline 14 & Cr I & 464.6 & 29 & O I & 777.4 \\
\hline
\end{tabular}



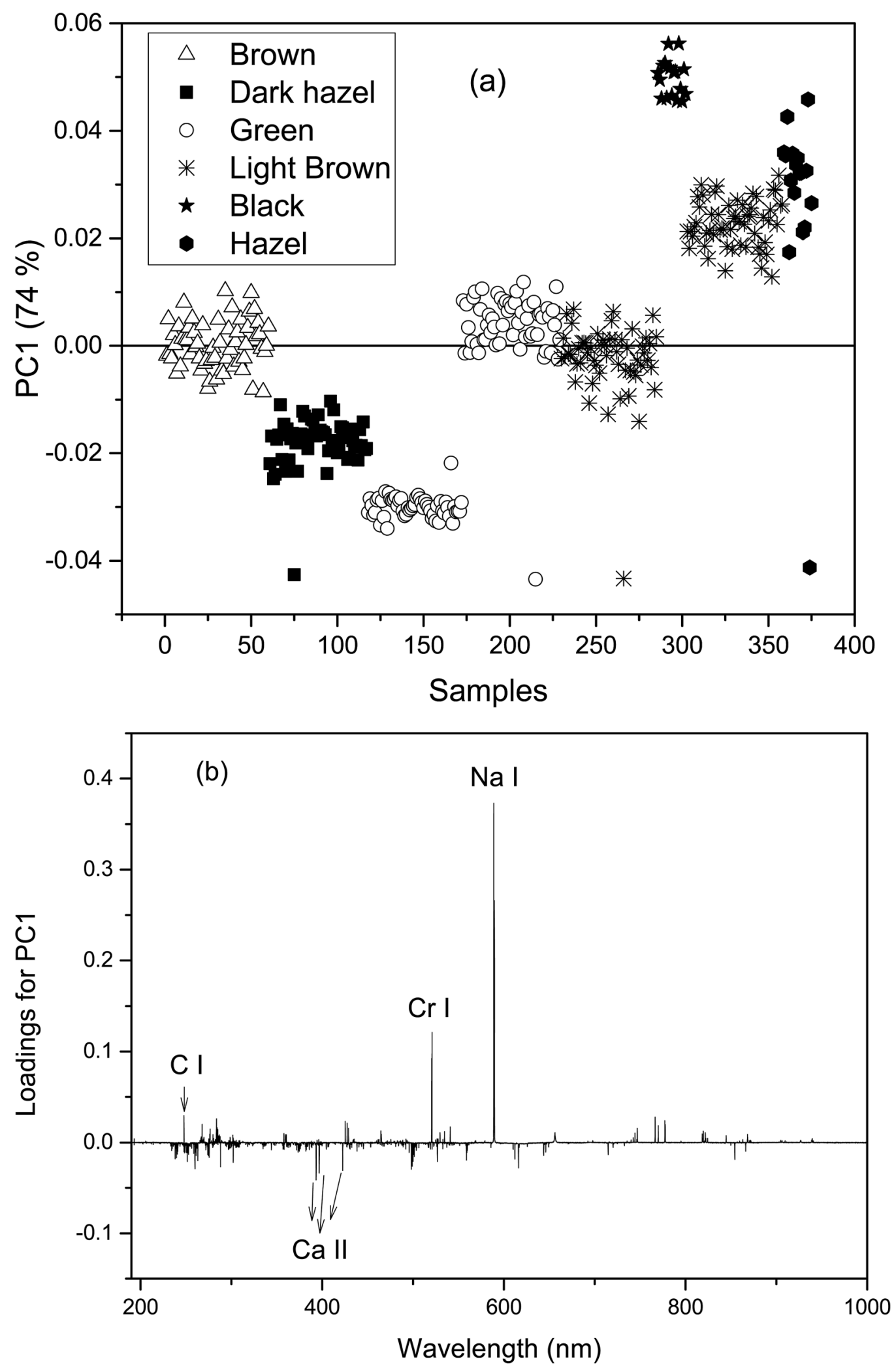

Fig. 4 PC1 scores plot (a) and PC1 loading plot (b) for the leather samples in different colors.

According to Fig. S5 (in the ESI $\dagger$ ), Cr and Na have influences on the positive values of $\mathrm{PC} 2$, and $\mathrm{C}, \mathrm{Mg}, \mathrm{Cr}, \mathrm{Ca}$ and $\mathrm{O}$ are responsible for the negative part of PC2. A separation among 6 leather colors can also be seen in Fig. S7 (in the ESI†), where the elements responsible for the separation are $\mathrm{Ca}, \mathrm{Na}$ and $\mathrm{O}$ for the positive values of PC 3 and $\mathrm{C}, \mathrm{Cr}$ and $\mathrm{K}$ for the negative values. 


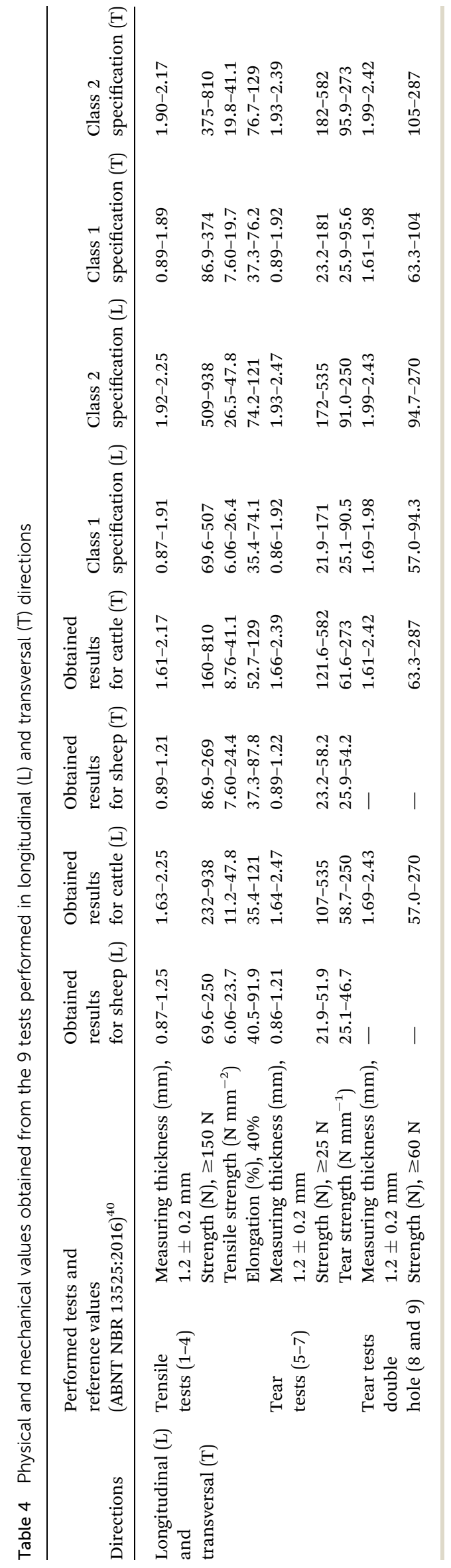

\section{Classification models proposition}

In this part of the study, the samples were divided into two classes. Table 4 presents the specifications elected for each test. These specifications were organized according to ABNT NBR 13525:2016 ${ }^{40}$ that was recently published and shows orientation values for acceptance of quality leather for physical and chemical testing. These values were used as orientation parameters to establish the classes, and attempts were made to keep $50 \%$ of the samples in each class.

For example, tests 1,5 and 8 are related to the thicknesses of the samples, and the reference value is $1.2 \pm 0.2 \mathrm{~mm}$. Sheep and cattle presented values varying from 0.870 to $2.25 \mathrm{~mm}$ and 0.890 to $2.17 \mathrm{~mm}$ in the longitudinal and transversal directions, respectively. In this case, samples with thickness lower than 1.91 for $\mathrm{L}$ and 1.89 for $\mathrm{T} \mathrm{mm}$ were grouped in class 1 .

These classes were then used to calculate classification models using the spectral information obtained by LIBS. Table 5 presents the values obtained when KNN was used to predict class 1 samples. The dataset was divided into calibration and validation, and 4 figures of merit were calculated: accuracy, sensitivity, specificity and false alarm rate. The average accuracy obtained for class 1 in the L direction was 78.8 for calibration and $76.1 \%$ for validation. Accuracy represents the percentage of correct predictions of the model. In the case of SIMCA and PLSDA, the accuracy presented similar results and varied from 71.6 to $80.5 \%$ for calibration and validation in the two classes. The sensitivity for class 1 is the ability of the model to correctly predict class 2 samples, and the results ranged from 61.6 to $84.6 \%$ for all calculated models. The false alarm rate is the number of incorrect predictions divided by the total number of samples for a specific class. The false alarm rate for the 3 calculated classification models varied from 14.4 to $36.9 \%$ for all models. The last figure of merit was the specificity, and this value computes the number of correct predictions for a specific class divided by the total number of samples from the same class. In general, the specificity goes from 61.6 to $84.6 \%$. The ideal situation is accuracy, sensitivity and specificity equal to $100 \%$ and false alarm rate equal to $0 \%$.

Tables 5 and 6 show the results for KNN for classes 1 and 2, respectively. Individual models were calculated for each test in the two evaluated directions. The number of selected neighbors varied from 3 to 5. Tables S3-S6 (all in the ESI + ) shows the results for SIMCA and PLS-DA. In general, the models proposed with PLS-DA were slightly better. Fig. 5 shows a receiver operating characteristics (ROC) ${ }^{41}$ curve for test 1 (measuring thickness in tensile tests, see Table 4$)$ in class 1 samples (0.87-1.91 for L and 0.89-1.89 for T) for PLS-DA calibration (Fig. 5a) and validation (Fig. $5 \mathrm{~b}$ ) data sets. The calculated area under the curves varied from 0.74 to 0.76 , and the models can be considered fair.

ROC curves for the other tests (from 2 to 9) are shown in Fig. S8-S11 at ESI. $\dagger$ In general the area under the curve varied from 0.6 (poor) to 0.9 (good).

Although classification models achieved around $80 \%$ correct classification, we believe that the models developed, will be useful for practical applications, because they are easy to implement in 
Table 5 Accuracy, sensitivity, false alarm rate and specificity obtained for class 1 of KNN model

Calibration class 1 Validation class 1

Number Number Accuracy Sensitivity False alarm Specificity Number of Accuracy Sensitivity False alarm Specificity Test Direction of samples of neighbors $(\%)$

\begin{tabular}{|c|c|c|c|c|c|c|c|c|c|c|c|c|}
\hline 1 & $\mathrm{~L}$ & 158 & 3 & 78.0 & 74.6 & 19.0 & 81.0 & 33 & 81.3 & 73.8 & 9.1 & 90.9 \\
\hline 2 & $\mathrm{~L}$ & 149 & 4 & 65.3 & 72.2 & 41.6 & 58.4 & 39 & 61.3 & 61.1 & 38.5 & 61.5 \\
\hline 3 & $\mathrm{~L}$ & 163 & 5 & 68.7 & 69.3 & 31.9 & 68.1 & 27 & 62.7 & 66.7 & 44.4 & 55.6 \\
\hline 4 & $\mathrm{~L}$ & 154 & 5 & 77.3 & 76.7 & 22.1 & 77.9 & 34 & 73.3 & 85.4 & 41.2 & 58.8 \\
\hline 5 & $\mathrm{~L}$ & 155 & 5 & 79.9 & 77.8 & 18.1 & 81.9 & 33 & 73.3 & 76.2 & 30.3 & 69.7 \\
\hline 6 & $\mathrm{~L}$ & 152 & 5 & 83.6 & 78.9 & 11.8 & 88.2 & 36 & 81.3 & 76.9 & 13.9 & 86.1 \\
\hline 7 & $\mathrm{~L}$ & 153 & 3 & 84.6 & 83.6 & 14.4 & 85.6 & 35 & 80.0 & 82.5 & 22.9 & 77.1 \\
\hline 8 & $\mathrm{~L}$ & 134 & 5 & 79.0 & 71.2 & 14.2 & 85.8 & 25 & 81.0 & 76.3 & 12.0 & 88.0 \\
\hline \multirow[t]{4}{*}{9} & $\mathrm{~L}$ & 127 & 3 & 92.9 & 88.8 & 3.1 & 96.9 & 31 & 90.5 & 87.5 & 6.5 & 93.5 \\
\hline & Average & & & 78.8 & 77.0 & 19.6 & 80.4 & & 76.1 & 76.3 & 24.3 & 75.7 \\
\hline & Median & & & 78.9 & 76.9 & 18.5 & 81.5 & & 78.0 & 76.3 & 23.6 & 76.4 \\
\hline & SD & & & 8.24 & 6.20 & 11.36 & 11.36 & & 9.45 & 8.49 & 14.74 & 14.74 \\
\hline 1 & $\mathrm{~T}$ & 156 & 5 & 77.0 & 70.1 & 16.7 & 83.3 & 34 & 77.3 & 75.6 & 20.6 & 79.4 \\
\hline 2 & $\mathrm{~T}$ & 160 & 3 & 69.3 & 71.4 & 32.5 & 67.5 & 29 & 76.0 & 78.3 & 27.6 & 72.4 \\
\hline 3 & $\mathrm{~T}$ & 149 & 5 & 70.3 & 69.5 & 28.9 & 71.1 & 39 & 69.3 & 66.7 & 28.2 & 71.8 \\
\hline 4 & $\mathrm{~T}$ & 151 & 6 & 91.3 & 92.6 & 9.9 & 90.1 & 37 & 85.3 & 86.8 & 16.2 & 83.8 \\
\hline 5 & $\mathrm{~T}$ & 156 & 5 & 80.6 & 76.2 & 15.4 & 84.6 & 32 & 84.0 & 81.4 & 12.5 & 87.5 \\
\hline 6 & $\mathrm{~T}$ & 154 & 3 & 77.7 & 74.7 & 19.5 & 80.5 & 33 & 83.8 & 78.0 & 9.1 & 90.9 \\
\hline 7 & $\mathrm{~T}$ & 155 & 3 & 82.3 & 80.6 & 16.1 & 83.9 & 33 & 81.3 & 73.8 & 9.1 & 90.9 \\
\hline 8 & $\mathrm{~T}$ & 131 & 5 & 76.2 & 72.7 & 20.6 & 79.4 & 25 & 79.4 & 73.7 & 12.0 & 88.0 \\
\hline \multirow[t]{4}{*}{9} & $\mathrm{~T}$ & 125 & 5 & 93.7 & 89.8 & 2.4 & 97.6 & 33 & 92.1 & 86.7 & 3.0 & 97.0 \\
\hline & Average & & & 79.8 & 77.5 & 18.0 & 82.0 & & 80.9 & 77.9 & 15.4 & 84.6 \\
\hline & Median & & & 78.7 & 75.4 & 17.3 & 82.7 & & 81.1 & 78.0 & 13.9 & 86.1 \\
\hline & SD & & & 8.33 & 8.47 & 9.07 & 9.07 & & 6.47 & 6.47 & 8.61 & 8.61 \\
\hline
\end{tabular}

Table 6 Accuracy, sensitivity, false alarm rate and specificity obtained for class 2 of KNN model

\begin{tabular}{|c|c|c|c|c|c|c|c|c|c|c|c|c|}
\hline \multirow[b]{2}{*}{ Test } & \multirow[b]{2}{*}{ Direction } & \multicolumn{6}{|c|}{ Calibration class 2} & \multicolumn{5}{|c|}{ Validation class 2} \\
\hline & & $\begin{array}{l}\text { Number } \\
\text { of } \\
\text { samples }\end{array}$ & $\begin{array}{l}\text { Number } \\
\text { of } \\
\text { neighbors }\end{array}$ & $\begin{array}{l}\text { Accuracy } \\
(\%)\end{array}$ & $\begin{array}{l}\text { Sensitivity } \\
(\%)\end{array}$ & $\begin{array}{l}\text { False } \\
\text { alarm } \\
\text { rate (\%) }\end{array}$ & $\begin{array}{l}\text { Specificity } \\
(\%)\end{array}$ & $\begin{array}{l}\text { Number } \\
\text { of } \\
\text { samples }\end{array}$ & $\begin{array}{l}\text { Accuracy } \\
(\%)\end{array}$ & $\begin{array}{l}\text { Sensitivity } \\
(\%)\end{array}$ & $\begin{array}{l}\text { False } \\
\text { alarm } \\
\text { rate (\%) }\end{array}$ & $\begin{array}{l}\text { Specificity } \\
(\%)\end{array}$ \\
\hline 1 & $\mathrm{~L}$ & 142 & 3 & 78.0 & 81.0 & 25.4 & 74.6 & 42 & 81.3 & 90.9 & 26.2 & 73.8 \\
\hline 2 & $\mathrm{~L}$ & 151 & 4 & 65.3 & 58.4 & 27.8 & 72.2 & 36 & 61.3 & 61.5 & 38.9 & 61.1 \\
\hline 3 & $\mathrm{~L}$ & 137 & 5 & 68.7 & 68.1 & 30.7 & 69.3 & 48 & 62.7 & 55.6 & 33.3 & 66.7 \\
\hline 4 & $\mathrm{~L}$ & 146 & 5 & 77.3 & 77.9 & 23.3 & 76.7 & 41 & 73.3 & 58.8 & 14.6 & 85.4 \\
\hline 5 & $\mathrm{~L}$ & 144 & 5 & 79.9 & 81.9 & 22.2 & 77.8 & 42 & 73.3 & 69.7 & 23.8 & 76.2 \\
\hline 6 & $\mathrm{~L}$ & 147 & 5 & 83.6 & 88.2 & 21.1 & 78.9 & 39 & 81.3 & 86.1 & 23.1 & 76.9 \\
\hline 7 & $\mathrm{~L}$ & 146 & 3 & 84.6 & 85.6 & 16.4 & 83.6 & 40 & 80.0 & 77.1 & 17.5 & 82.5 \\
\hline 8 & $\mathrm{~L}$ & 118 & 5 & 79.0 & 85.8 & 28.8 & 71.2 & 38 & 81.0 & 88.0 & 23.7 & 76.3 \\
\hline \multirow[t]{4}{*}{9} & $\mathrm{~L}$ & 125 & 3 & 92.9 & 96.9 & 11.2 & 88.8 & 32 & 90.5 & 93.5 & 12.5 & 87.5 \\
\hline & Average & & & 78.8 & 80.4 & 23.0 & 77.0 & & 76.1 & 75.7 & 23.7 & 76.3 \\
\hline & Median & & & 78.9 & 81.5 & 23.1 & 76.9 & & 78.0 & 76.4 & 23.7 & 76.3 \\
\hline & $\mathrm{SD}$ & & & 8.24 & 11.36 & 6.20 & 6.20 & & 9.45 & 14.74 & 8.49 & 8.49 \\
\hline 1 & $\mathrm{~T}$ & 144 & 5 & 77.0 & 83.3 & 29.9 & 70.1 & 41 & 77.3 & 79.4 & 24.4 & 75.6 \\
\hline 2 & $\mathrm{~T}$ & 140 & 3 & 69.3 & 67.5 & 28.6 & 71.4 & 46 & 76.0 & 72.4 & 21.7 & 78.3 \\
\hline 3 & $\mathrm{~T}$ & 151 & 5 & 70.3 & 71.1 & 30.5 & 69.5 & 36 & 69.3 & 71.8 & 33.3 & 66.7 \\
\hline 4 & $\mathrm{~T}$ & 148 & 6 & 91.3 & 90.1 & 7.4 & 92.6 & 38 & 85.3 & 83.8 & 13.2 & 86.8 \\
\hline 5 & $\mathrm{~T}$ & 143 & 5 & 80.6 & 84.6 & 23.8 & 76.2 & 43 & 84.0 & 87.5 & 18.6 & 81.4 \\
\hline 6 & $\mathrm{~T}$ & 146 & 3 & 77.7 & 80.5 & 25.3 & 74.7 & 41 & 83.8 & 90.9 & 22.0 & 78.0 \\
\hline 7 & $\mathrm{~T}$ & 144 & 3 & 82.3 & 83.9 & 19.4 & 80.6 & 42 & 81.3 & 90.9 & 26.2 & 73.8 \\
\hline 8 & $\mathrm{~T}$ & 121 & 5 & 76.2 & 79.4 & 27.3 & 72.7 & 38 & 79.4 & 88.0 & 26.3 & 73.7 \\
\hline \multirow[t]{4}{*}{9} & $\mathrm{~T}$ & 127 & 5 & 93.7 & 97.6 & 10.2 & 89.8 & 30 & 92.1 & 97.0 & 13.3 & 86.7 \\
\hline & Average & & & 79.8 & 82.0 & 22.5 & 77.5 & & 80.9 & 84.6 & 22.1 & 77.9 \\
\hline & Median & & & 78.7 & 82.7 & 24.6 & 75.4 & & 81.1 & 86.1 & 22.0 & 78.0 \\
\hline & $\mathrm{SD}$ & & & 8.33 & 9.07 & 8.47 & 8.47 & & 6.47 & 8.61 & 6.47 & 6.47 \\
\hline
\end{tabular}



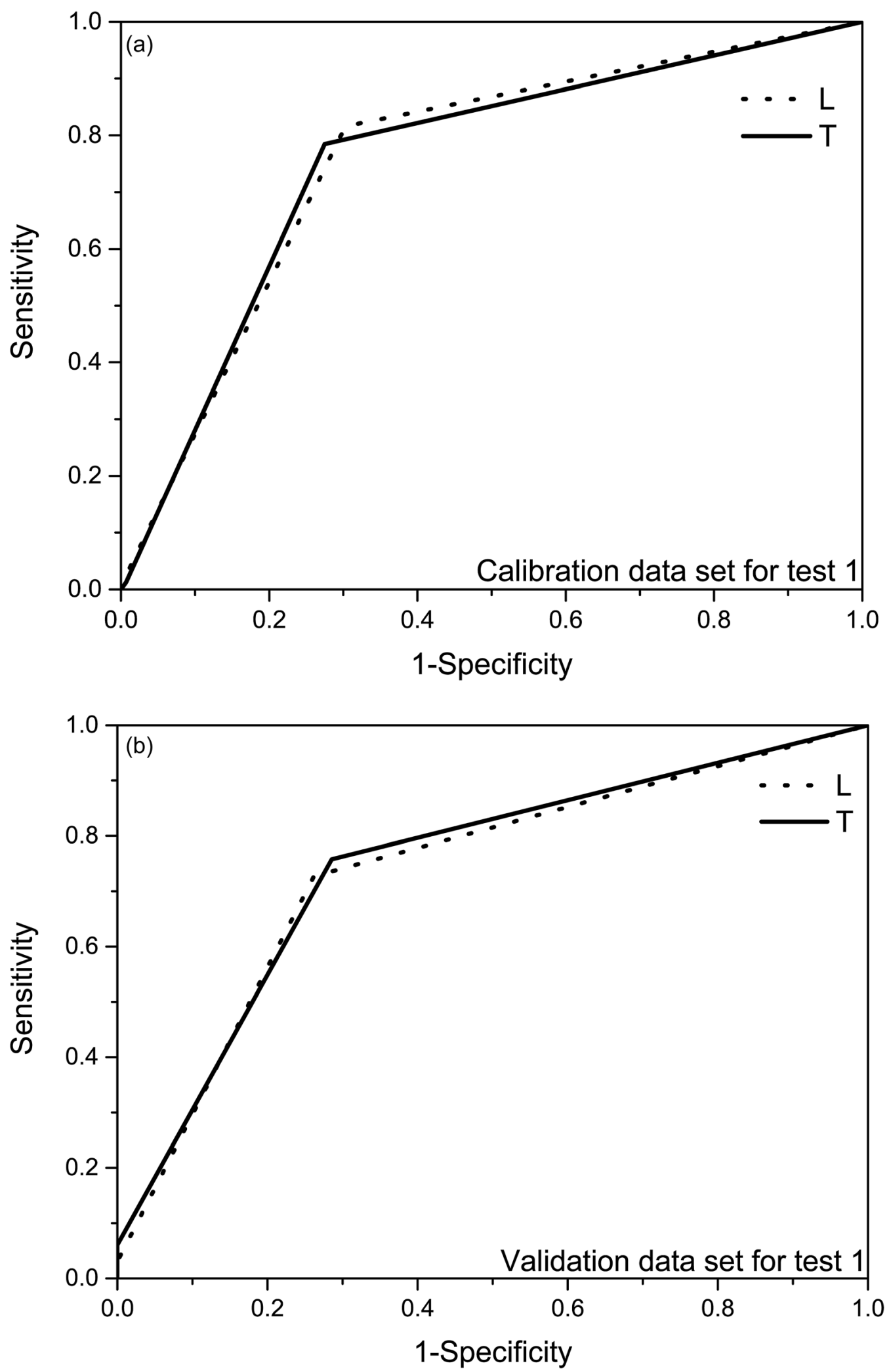

Fig. 5 ROC curves for class 1 samples in PLS-DA calibration (a) and validation (b) data sets (see test identification in Table 4). Solid and dotted lines represents tests performed in transversal $(T)$ and longitudinal $(L)$ directions, respectively.

industrial field and can offer preliminary results. In addition, suspicious values can be further confirmed with standard methods. Whereas traditional testing to ensure the quality of the leather is too laborious, time-consuming and requires large amount of leather, so the leather used in the tests will be destroyed and discarded, thus reducing its economical value. In 
addition, generally physical and mechanical tests are performed in private laboratories, adding higher production costs, thus prevents a quality control more strictly, because only a small part of the leathers will be submitted to the tests. In this case, around $80 \%$ of correct classification should be enough. Using LIBS alternatively coupled to a classification model, the analysis could be made in the tannery itself with a portable LIBS, for example. This approach can present a high analytical frequency without damaging the leather, which can be further commercialized (without it being necessary to cut pieces). Finally, the proposed method can increase profit at the time of sale, in addition as it takes only a few seconds for analysis, this way all leathers could be inspected, and determine the quality of $100 \%$ of leather produced and not just a fraction as is usually done.

\section{Conclusions}

Classification models (KNN, SIMCA and PLS-DA) were developed using LIBS emission spectra and associated with physical mechanical tests on leather as reference values. The predictive abilities of the models were similar, showing that three models can be used to predict leather quality for sheep and cattle satisfactorily. The models generate concordant predicted results with the reference values for the physical mechanical tests in both evaluated directions, demonstrating the potential of using this tool in combination with LIBS to predict the quality of sheep and cattle leathers using a single model. The proposed method is fast, and no chemical residues are generated.

\section{Acknowledgements}

This study was supported by the São Paulo Research Foundation (FAPESP, process 2015/14488-0), Empresa Brasileira de Pesquisa Agropecuária (Embrapa, 02.03.1.16.00.08) and Conselho Nacional de Desenvolvimento Científico e Tecnológico (CNPq, 506119/2008-4, 401074/2014-5 and 305637/2015-0).

\section{Notes and references}

1 E. Alptekin, M. Canakci and H. Sanli, Fuel, 2012, 95, 214-220.

2 M. J. Ferreira, M. F. Almeida, S. C. Pinho and I. C. Santos, Waste Manage., 2010, 30, 1091-1100.

3 S. Dixit, A. Yadav, P. D. Dwivedi and M. Das, J. Cleaner Prod., 2015, 87, 39-49.

4 G. L. Scheffler and D. Pozebon, Anal. Methods, 2015, 7, 51805185.

5 International Organization For Standardization-ISO 2419, Leather-Physical and mechanical tests-Sample preparation and conditioning, Geneva, 2006, p. 3.

6 Associação Brasileira De Normas Técnicas-ABNT NBR ISO 2418:2015, Leather-Chemical, physical and mechanical and fastness test-Sampling Location, Rio de Janeiro, 2015, p. 7.

7 D. C. Deselnicu, Leather and Footwear Journal, 2010, 10, 1330 .

8 A. Aslan and N. O. Üzüm, Tekstil ve Konfeksiyon, 2015, 25, 3337.
9 H. A. Karavana, B. Başaran, A. Aslan, B. O. Bitlisli and G. Gülümser, Tekstil ve Konfeksiyon, 2011, 3, 305-310.

10 A. Aslan, Bull Environ. Contam. Toxicol., 2009, 82, 633-638.

11 S. Okoh, D. J. Adeyemo, R. A. Onoja and S. A. Arabi, Int. J. Appl. Sci. Technol., 2013, 3, 101-105.

12 P. Budrugeac, A. Cucos and L. Miu, J. Therm. Anal. Calorim., 2011, 104, 439-450.

13 R. Cantero, J. R. Riba, T. Canals, L. L. Izquierdo and H. Iturriaga, J. Soc. Leather Technol. Chem., 2008, 93, 12-17.

14 M. M. Nasr, M. A. Gondal and Z. S. Seddigi, Environ. Monit. Assess., 2011, 175, 387-395.

15 R. Cantero, T. Canals and H. Iturriaga, Talanta, 2007, 71, 1690-1695.

16 Q. Godoi, F. O. Leme, L. C. Trevizan, E. R. Pereira-Filho, I. A. Rufini, D. Santos Jr and F. J. Krug, Spectrochim. Acta, Part B, 2011, 66, 138-143.

17 M. J. C. Pontes, J. Cortez, R. K. H. Galvão, C. Pasquini, M. C. U. Araújo, R. M. Coelho, M. K. Chiba, M. F. Abreu and B. E. Madari, Anal. Chim. Acta, 2009, 642, 12-18.

18 A. K. Myakalwar, S. Sreedhar, I. Barman, N. C. Dingari, S. V. Rao, P. P. Kiran, S. P. Tewari and G. M. Kumar, Talanta, 2011, 87, 53-59.

19 M. R. Martelli, F. Brygo, A. Sadoudi, P. Delaporte and C. Barron, J. Agric. Food Chem., 2010, 58, 7126-7134.

20 M. Hoehse, A. Paul, I. Gornushkin and U. Panne, Anal. Bioanal. Chem., 2012, 402, 1443-1450.

21 C. A. Munson, F. C. Lucia Jr, T. Piehler, K. L. McNesby and A. W. Miziolek, Spectrochim. Acta, Part B, 2005, 60, 12171224.

22 F. M. V. Pereira, D. M. B. P. Milori, A. L. Venancio, M. S. T. Russo, P. K. Martins and J. Freitas-Astua, Talanta, 2010, 83, 351-356.

23 P. M. Mukhono, K. H. Angeyo, A. Dehayem-Kamadjeu and K. A. Kaduki, Spectrochim. Acta, Part B, 2013, 87, 81-85.

24 F. W. B. Aquino and E. R. Pereira-Filho, Talanta, 2015, 134, $65-73$.

25 F. W. B. Aquino, J. M. Santos, R. R. V. Carvalho, J. A. O. Coelho and E. R. Pereira-Filho, RSC Adv., 2015, 5, 67001-67010.

26 J. B. Sirven, A. Pailloux, Y. M'Baye, N. Coulon, T. Alpettaz and S. Gossé, J. Anal. At. Spectrom., 2009, 24, 451-459.

27 M. M. C. Ferreira, Quimiometria: conceitos, métodos e aplicações, Unicamp, Campinas, 2015.

28 D. Custers, S. Vandemoortele, J. L. Bothy, J. O. De Beer, P. Courselle, S. Apers and E. Deconinck, Drug Test. Anal., 2016, 8, 378-387.

29 Associação Brasileira De Normas Técnicas-ABNT NBR 10455:2014, Climate of materials used in footwear and related articles manufacture, Rio de Janeiro, 2014, p. 2.

30 Associação Brasileira De Normas Técnicas-ABNT NBR ISO 2589:2014, Leather-Physical and mechanical testsDetermination of thickness, Rio de Janeiro, 2014, p. 2.

31 Associação Brasileira De Normas Técnicas-ABNT NBR ISO 3376:2014, Leather-Physical and mechanical testsDetermination of tensile strength and percentage extension, Rio de Janeiro, 2014, p. 5. 
32 Associação Brasileira De Normas Técnicas-ABNT NBR ISO 3377-1:2014, Leather-Physical and mechanical testsDetermination of tear load, Part 1: Single edge tear, Rio de Janeiro, 2014, p. 4.

33 Associação Brasileira De Normas Técnicas-ABNT NBR ISO 3377-2:2014, Leather-Physical and mechanical testsDetermination of tear load Part 2: Tear double-edged, Rio de Janeiro, 2014, p. 3.

34 S. L. C. Ferreira, W. N. L. Santos, C. M. Quintella, B. B. Neto and J. M. Bosque-Sendra, Talanta, 2004, 63, 1061-1067.

35 M. C. Breitkreitz, A. M. Souza and R. J. Poppi, Quim. Nova, $2014,37,564-573$.
36 J. P. Castro and E. R. Pereira-Filho, J. Anal. At. Spectrom., 2016, 31, 2005-2014.

37 M. M. C. Ferreira, J. Braz. Chem. Soc., 2002, 13, 742-753.

38 D. Ballabio and V. Consonni, Anal. Methods, 2013, 5, 37903798.

39 M. Daszykowski, B. Walczak and D. L. Massart, Anal. Chim. Acta, 2002, 468, 91-103.

40 Associação Brasileira De Normas Técnicas-ABNT NBR 13525:2016, Physical and chemical testing of leatherorientation values for acceptance of leather, Rio de Janeiro, 2014, p. 10.

41 C. D. Brown and H. T. Davis, Chemom. Intell. Lab. Syst., 2006, 80, 24-38. 